\title{
Mechanism of Exaggerated Natriuresis
}

\section{in Hypertensive Man: Impaired \\ Sodium Transport in the Loop of Henle}

\author{
Vardaman M. Buckalew, Jr., Jules B. Puschett, James E. Kintzel, and \\ MARTIN GOLDBERG \\ From the Renal-Electrolyte Section, Department of Medicine, University of \\ Pennsylvania School of Medicine, Philadelphia, Pennsylvania 19104
}

A B S T R A C T To evaluate the effects of saline loading on distal sodium reabsorption in hypertensive man, studies were performed during both water deprivation and water diuresis in eight hypertensive subjects, and the results were compared to data obtained from similar studies in normal subjects. All hypertensive patients exhibited an enhanced excretion of filtered sodium $\left(\mathrm{C}_{\mathrm{N}_{\mathrm{a}}} / \mathrm{C}_{\mathrm{In}}\right)$ at any level of distal delivery of sodium compared to normal controls. Free water reabsorption $\left(\mathrm{T}_{\mathrm{H}_{2} \mathrm{O}}\right)$ during hypertonic saline loading was quantitatively abnormal in the hypertensives at high levels of osmolar clearance (Cosm), and also the curve of $\mathrm{T}^{\mathbf{c}} \mathrm{H}_{20}$ vs. Cosm leveled off above a Cosm of $18 \mathrm{ml} / \mathrm{min}$ per 1.73 $\mathrm{m}^{2}$ in the hypertensive group in contrast to the normal controls in whom $\mathrm{T}^{\mathrm{c}}{ }_{\mathrm{H}_{2} \mathrm{O}}$ showed no evidence of achieving an upper limit. Sodium depletion exaggerated the abnormality in $\mathrm{T}^{\mathrm{c}} \mathrm{H}_{2} \mathrm{O}$ in hypertensives, and resulted in a positive free water clearance $\left(\mathrm{C}_{\mathrm{H}_{2} \mathrm{O}}\right)$ during hydropenia.

During hypotonic saline loading in water diuresis, changes in free water clearance per $100 \mathrm{ml}$ of glomerular filtrate $\left(\mathrm{C}_{\mathrm{H}_{2}} / \mathrm{C}_{\mathrm{In}}\right)$ were less at any given increment in urine flow per $100 \mathrm{ml}$ of glomerular filtrate $\left(\mathrm{V} / \mathrm{C}_{\mathrm{In}}\right)$ in the hypertensives compared to normal controls $(P<$ 0.001 ). This abnormality in $\mathrm{C}_{\mathrm{H}_{2} \mathrm{O}} / \mathrm{C}_{\mathrm{In}}$ in the hypertensives in conjunction with the defect in $\mathrm{T}_{\mathrm{H}_{2} \mathrm{O}}^{\mathrm{e}}$ observed during hydropenia indicates that sodium reabsorption in the loop of Henle was abnormal at any given rate of distal delivery of sodium in hypertension. Furthermore, these abnormalities in $\mathrm{T}^{\mathrm{e}}{ }_{\mathrm{H}_{2} \mathrm{O}}$ and $\mathrm{C}_{\mathrm{H}_{2} \mathrm{O}}$ coincided temporally with the development of the exaggerated natriuresis. Although the distal defect in sodium transport, in large part, accounted for the augmented natriuresis in hyper-

This work was presented in part at the 1st Annual Meeting of the American Society of Nephrology, Los Angeles, Calif., 18 October 1967.

Received for publication 29 October 1968 and in revised form 29 January 1969. tension, evidence was present also for enhanced rejection of sodium in the proximal tubule during saline loading in the hypertensives.

Additional studies utilizing acetazolamide which increases distal delivery of sodium without extracellular fluid volume expansion showed only minimal abnormalities in $\mathrm{C}_{\mathrm{H}_{2} \mathrm{O}}$ in the hypertensive group, indicating that the defect in sodium transport in the loop of Henle in hypertensives is mainly an abnormal response to extracellular fluid expansion rather than an intrinsic defect in the loop to handle increased tubular loads of sodium. It is possible that the abnormality in sodium reabsorption in the loop of Henle is due to the transmission of the abnormally elevated blood pressure of the hypertensives to the medullary vasa recta during saline loading.

\section{INTRODUCTION}

Numerous investigators have demonstrated that acute volume expansion in patients with hypertension results in a more prompt rise in sodium excretion than is seen in the normotensive subject (1-3). This phenomenon, which has been referred to as an "exaggerated natriuresis," has been attributed both to decreased tubular sodium reabsorption $(2,3)$ and to increased glomerular filtration rate (GFR) (2), but the intrarenal mechanisms have not been precisely defined.

Much work has been recently reported on the renal mechanisms regulating the rate of sodium excretion after acute volume expansion in normal animals (4-7). Although a rise in GFR theoretically might contribute to the natriuresis, recent work in dogs indicates that isolated changes in GFR per se do not result in significant alterations in sodium excretion (8). Therefore, it appears that changes in tubular reabsorption of sodium are of prime importance in determining the magnitude of 
the natriuresis after volume expansion. Although decreased proximal tubular reabsorption clearly results from volume expansion, a large fraction of the sodium rejected proximally may be reabsorbed in the distal nephron $(4-7,9,10)$. Thus, the amount of sodium finally excreted during volume expansion is in large part a function of factors which regulate sodium reabsorption in the loop of Henle and other distal structures. According to these concepts, the "exaggerated natriuresis" of hypertensive subjects could be due to: (a) a greater than normal decrease in the fraction of filtered sodium reabsorbed in the proximal tubule; $(b)$ a decrease in the ratio of the sodium reabsorbed distally to the rate of sodium delivery to the loop from the proximal tubule; or $(c)$ some combination of these two factors.

The present study was designed to evaluate sodium reabsorption in the loop of Henle under conditions of increased delivery of sodium to the loop in the hypertensive subject. Sodium reabsorption in the loop of Henle is responsible for both the concentration and dilution of urine. Therefore, the rate of free water reabsorption $\left(\mathrm{T}^{\mathbf{c}} \mathrm{H}_{2} \mathrm{O}\right)$ during hydropenia, and free water clearance $\left(\mathrm{C}_{\mathrm{H}_{2} \mathrm{O}} \mathrm{O}\right.$ during water diuresis, are indirect indices of sodium reabsorption in the loop. In hydropenic subjects, sodium delivery was increased by volume expansion with hypertonic saline, and in water-loaded subjects by the infusion of hypotonic saline. $\mathrm{C}_{\mathrm{H}_{2} \mathrm{O}}$ was also measured in hydrated subjects after the administration of acetazolamide, a drug which has a major action in the proximal tubule to decrease the reabsorption of sodium and bicarbonate. This procedure provided a means of increasing sodium delivery to the loop without the necessity of expanding the subject's extracellular fluid volume.

The results indicate that in saline-loaded hypertensive patients, sodium reabsorption in the loop of Henle is reduced at any rate of delivery compared to the normal subjects. This phenomenon is a major factor in the "exaggerated natriuresis" of hypertension.

\section{METHODS}

Studies were performed in eight hypertensive patients and six normal male volunteers. All patients were admitted to the Clinical Research Center of the Hospital of the University of Pennsylvania. Both the patients and normal subjects ingested a diet containing at least $150 \mathrm{mEq}$ of sodium for several days before each study except where indicated below. All medication had been discontinued for at least 10 days before study. Two of the patients (T. N. and F. G) had the typical picture of primary hyperaldosteronism and were found to have solitary adrenal adenomas at laparotomy. These two patients became normotensive after surgical removal of the tumors. A third patient (P. L.) had hyperaldosteronism, and at laparotomy was found to have bilateral nodular adrenal hyperplasia. This patient underwent bilateral total adrenalectomy and 2 years after operation continued to have hypertension, although of a milder degree. The patients with hyperaldosteronism were studied while they were potassium depleted and P. L. was studied again postoperatively after potassium repletion. The remainder of the patients had typical essential hypertension with moderate to severe elevation of blood pressure.

Measurement of $\mathrm{T}^{\mathbf{c}}{ }_{\mathrm{H}_{2} \mathrm{O}}$ during hypertonic (3\%) saline diuresis in six hydropenic hypertensive patients was performed as previously described from this laboratory (9). Experiments were performed in the morning with patients in the recumbent position. Four of these patients (I. W., D. B., T. N., and P. L.) were studied while ingesting a high sodium diet as described above. Studies during ingestion of a low sodium diet (less than $20 \mathrm{mEq} /$ day) were performed in addition on patient P. L. and in two other hypertensive patients (F. G. and L. C.). The data on changes in $\mathrm{T}^{\mathrm{c}} \mathrm{H}_{2} \mathrm{O}$ and sodium excretion from these patients were compared with data obtained from six normal hydropenic subjects given hypertonic saline, studied similarly in this laboratory and reported previously (9). Maximum urine osmolality was determined after a standard protocol of fluid deprivation and Pitressin administration (11).

Studies of the renal diluting mechanism during maximal water diuresis were performed in six normal subjects and four hypertensive patients. Two of these patients ( $P$. L. and I. W.) were studied both during hydropenia and water diuresis. All subjects were deprived of food but not water for $12 \mathrm{hr}$ before study. Sustained water diuresis was obtained by the administration of $20 \mathrm{ml} / \mathrm{kg}$ of tap water orally, followed by an amount of water by mouth exactly equal to urine flow plus $0.8-1.0 \mathrm{ml} / \mathrm{min}$ to replace insensible losses. When a steady state of urine flow (V) had been obtained wherein the values for $\mathrm{V}$ for three consecutive collection periods were within $1.5 \mathrm{ml} / \mathrm{min}$ of each other, one of the following two protocols was utilized: $(a)$ hypotonic "saline" (Na, $130 \mathrm{mEq} /$ liter; $\mathrm{Cl}, 108 \mathrm{mEq} /$ liter $; \mathrm{HCO}_{3}, 22 \mathrm{mEq} /$ liter) was infused intravenously at increasing rates until at least 2 liters of infusate was given to four patients and six normal volunteers; (b) acetazolamide was administered in a separate study in a dose of $500 \mathrm{mg}$ intravenously to the same four hypertensive patients who received hypotonic saline and the changes in $\mathrm{V}$ were observed until diuresis subsided. During the above infusions water was given by mouth in amounts equal to those administered during the control steady-state water diuresis. No attempt was made to replace the sodium and water losses resulting from the acetazolamide diuresis. The data on changes in $\mathrm{C}_{\mathrm{H}_{2} \mathrm{O}}$ due to acetazolamide in the patients were compared to data obtained from a group of five maximally hydrated normal subjects studied by identical methods. ${ }^{1}$

Blood and urine specimens were collected at intervals of 30-45 min, and they were analyzed for osmolality, sodium, potassium, inulin, and $p$-aminohippuric acid (PAH) by methods previously described (9). $\mathrm{C}_{\mathrm{H}_{2} \mathrm{O}}, \mathrm{T}^{\mathbf{c}}{ }_{\mathrm{H}_{2} \mathrm{O}}$, and the clearances of inulin and PAH were calculated by standard formulae. Statistical analyses were performed by standard techniques (12).

\section{RESULTS}

\section{Studies during hydropenia}

Free water reabsorption. Hypertonic (3\%) saline was administered to four hypertensive subjects on a

${ }^{1}$ Buckalew, V. M., Jr., M. Goldberg, B. R. Walker, and J. B. Puschett. Sodium reabsorption at the renal diluting sites in normal man. Submitted for publication. 
TABLE I

Hypertonic Saline Diuresis in Hypertensive Subject, I. W.

\begin{tabular}{|c|c|c|c|c|c|c|}
\hline Time & Cosm* & $\mathrm{T}^{\circ} \mathrm{H}_{20} \mathrm{O}^{*}$ & $\mathrm{C}_{\mathrm{In}^{*}}$ & $\mathrm{C}_{\mathrm{PAH}} \mathrm{H}^{*}$ & $\frac{C_{N a}}{C_{I n}} \times 100$ & $\frac{\mathrm{C}_{\text {In }}}{\mathrm{C}_{\mathrm{PA} \mathrm{H}}} \times 100$ \\
\hline $\min$ & $m l / m i n$ & $m l / m i n$ & $m l / m i n$ & $m l / \min$ & & \\
\hline $0-65$ & 4.6 & 2.2 & 142 & 545 & 2.1 & 26 \\
\hline \multicolumn{7}{|c|}{ Begin $3 \% \mathrm{NaCl}$ infusion at $12 \mathrm{ml} / \mathrm{min}$} \\
\hline $65-88$ & 4.9 & 2.7 & 142 & 657 & 2.4 & 22 \\
\hline $88-108$ & 9.3 & 4.6 & 143 & 657 & 5.3 & 22 \\
\hline $108-118$ & 13.9 & 5.7 & 148 & 668 & 8.4 & 22 \\
\hline $118-128$ & 17.8 & 6.2 & 132 & 624 & 13.1 & 21 \\
\hline $128-137$ & 21.6 & 6.1 & 147 & 690 & 14.2 & 21 \\
\hline $137-145$ & 26.3 & 6.2 & 139 & 723 & 18.4 & 19 \\
\hline $145-151$ & 27.0 & 5.4 & 132 & 652 & 20.5 & 20 \\
\hline $151-157$ & 31.1 & 5.8 & 140 & 734 & 22.1 & 19 \\
\hline $157-162$ & 31.8 & 5.5 & 138 & 739 & 23.0 & 19 \\
\hline
\end{tabular}

Abbreviations: $\mathrm{C}_{\mathrm{Osm}}=$ osmolar clearance; $\mathrm{T}_{\mathrm{H}_{2} \mathrm{O}}=$ free water reabsorption $; \mathrm{C}_{\mathrm{In}_{\mathrm{n}}}=$ inulin clearance; $\mathrm{C}_{\mathrm{PAH}}=\mathrm{PAH}$ clearance. * Values corrected to $1.73 \mathrm{~m}^{2}$ body surface area.

high sodium intake, two with essential hypertension (I. W. and D. B.) and two with hyperaldosteronism (T. N. and P. L.). The protocol of a typical study is shown in Table I, and the relationship between osmolar clearance $\left(\mathrm{Cosm}_{\mathrm{s}}\right.$ ) and $\mathrm{T}_{\mathrm{H}_{2} \mathrm{O}}^{\mathrm{c}}$ for this patient is illustrated in Fig. 1 along with data from a representative study in a normal subject. The administration of hypertonic saline caused a prompt rise in V, Cosm, and $\mathrm{T}^{{ }^{*} \mathrm{H}_{2} \mathrm{O}}$ in both the patient and the normal subject. However, in the hypertensive patient at a Cosm of $18 \mathrm{ml} / \mathrm{min}$ per $1.73 \mathrm{~m}^{2}, \mathrm{~T}^{\mathrm{c}} \mathrm{H}_{2 \mathrm{O}} \mathrm{O}$ reached an apparent maximum of approximately $6.0 \mathrm{ml} / \mathrm{min}$ per $1.73 \mathrm{~m}^{2}$, and did not rise further as Cosm continued to rise to $32 \mathrm{ml} / \mathrm{min}$ per $1.73 \mathrm{~m}^{2}$. Similar results were obtained in the three other hypertensive subjects in which the apparent limits to

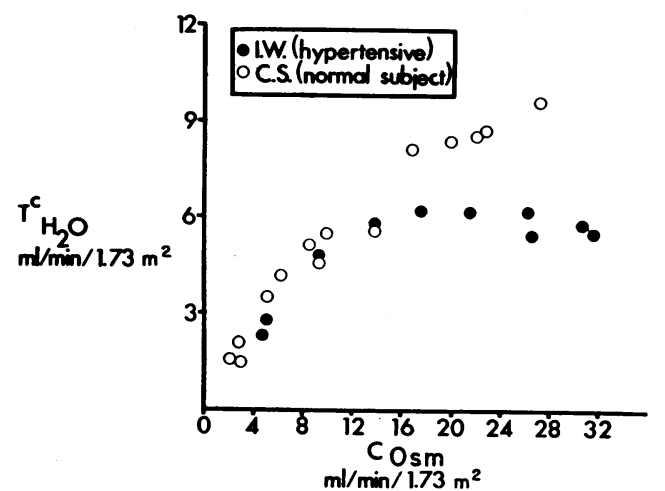

FIgURE 1 Hypertonic saline loading during hydropenia. Effects on free water reabsorption $\left(\mathrm{T}^{\mathbf{c}}{ }_{\mathrm{H}_{2} \mathrm{O}}\right)$ and osmolar clearance $\left(\mathrm{C}_{\mathrm{osm}}\right)$ in hypertensive patient I. W. (closed circles) and normal subject C. S. (open circles). The curve levels off in the hypertensive patient compared to normal. See text.
$\mathrm{T}^{\mathrm{c}}{ }_{\mathrm{H} 2 \mathrm{O}}$ were approximately $3.0,5.5$, and $5.5 \mathrm{ml} / \mathrm{min}$ per $1.73 \mathrm{~m}^{2}$, respectively. These results are in contrast to the data obtained from the normal subject illustrated which is representative of a group of normal volunteers previously studied in whom the infusion of hypertonic saline produced a rise in $\mathrm{T}_{\mathrm{H}_{2} \mathrm{O}}^{\mathrm{c}}$ without an apparent limit (9).

In Fig. 2 are composite data on the relationship between Cosm and $\mathrm{T}^{\mathrm{c}} \mathrm{H}_{2} \mathrm{O}$ in the four hypertensive and five normal subjects. The data are grouped so that $T^{\mathbf{c}}{ }_{\mathrm{H}_{2} \mathrm{O}}$ can be compared for each group at three levels of Cosm, i.e., 8,17 , and $24 \mathrm{ml} / \mathrm{min}$ per $1.73 \mathrm{~m}^{2}$. Each point represents the mean \pm 2 sEM. The difference in $\mathrm{T}^{\mathrm{e}} \mathrm{H}_{20}$ between the two groups was statistically significant at each of the three levels of Cosm. Maximum urine osmolality after fluid deprivation and Pitressin in these four hypertensive patients varied from 705 to $838 \mathrm{mOsm} / \mathrm{kg}$.

Free water reabsorption during low sodium intake. Hypertonic saline diuresis studies were also performed

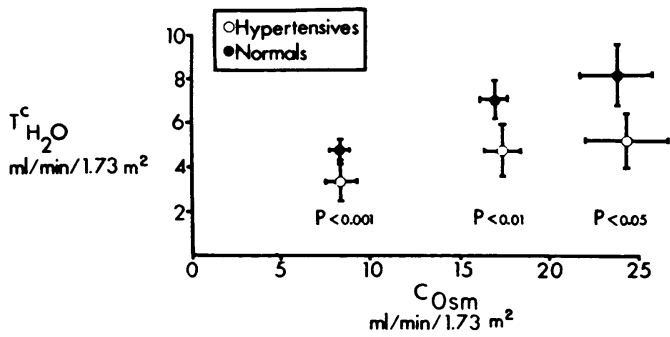

FIGURE 2 Hypertonic saline loading during hydropenia. Comparison of values of free water reabsorption $\left(\mathrm{T}^{\mathrm{c}}{ }_{\mathrm{H}_{2} \mathrm{O}}\right)$ at three levels of osmolar clearance ( $\mathrm{C}_{0 \mathrm{sm}}$ ) in normal subjects (closed circles) and hypertensive patients (open circles). Data represent means \pm 2 sEM. See text. 


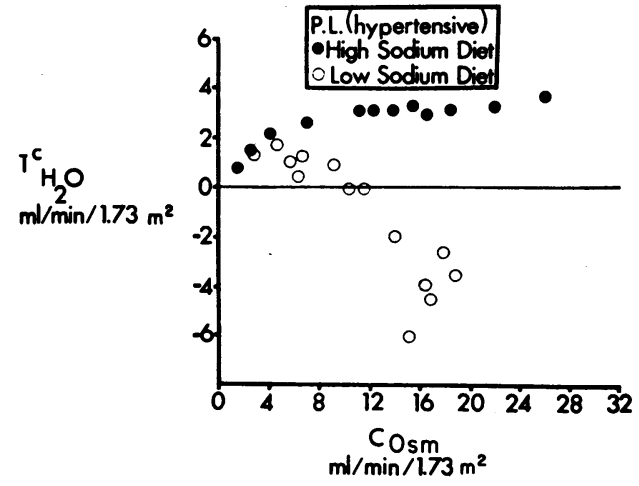

Figure 3 Hypertonic saline loading during hydropenia. Changes in free water reabsorption $\left(\mathrm{T}^{\mathrm{c}}{ }_{\mathrm{H}_{2} \mathrm{O}}\right.$ ) vs. osmolar clearance $\left(\mathrm{C}_{\mathrm{osm}}\right)$ in hypertensive patient $\mathrm{P}$. L. on high sodium diet (closed circles) and low sodium diet (open circles).

in three hypertensive patients (F. G., P. L., and L. C.) ingesting less than $20 \mathrm{mEq}$ of sodium per day. The effect of this procedure is well illustrated in Fig. 3 in patient P. L. in whom two studies were performed, one on a low sodium intake and one on a high sodium intake. It can be seen that on the low sodium diet, $\mathrm{T}^{\mathbf{c}}{ }_{\mathrm{H}_{2} \mathrm{O}}$ rose initially, then decreased to zero, and at high rates of Cosm became negative. In contrast, on the high sodium intake, the relationship between $T^{e_{H_{2} O}}$ and Cosm was similar to that described above for other hypertensive subjects. In two other studies in hypertensive subjects on low sodium intakes, similar results were obtained. In one patient (F. G.) negative $\mathrm{T}^{\mathbf{}_{\mathrm{H}} \mathrm{O}}$ was also observed at high Cosm. In the other patient (L. C.) $\mathrm{T}^{\mathrm{e}} \mathrm{H}_{2} \mathrm{O}$ rose to $5.6 \mathrm{ml} / \mathrm{min}$ per $1.73 \mathrm{~m}$ ' at a $C_{0 s m}$ of $17 \mathrm{ml} /$ min per $1.73 \mathrm{~m}^{2}$; and as Cosm increased to $30.3 \mathrm{ml} / \mathrm{min}$ per $1.73 \mathrm{~m}^{2}, \mathrm{~T}^{\circ}{ }_{\mathrm{H}_{2} \mathrm{O}}$ fell progressively to $1.6 \mathrm{ml} / \mathrm{min}$ per $1.73 \mathrm{~m}^{2}$.

Renal hemodynamics. During the control period, data on renal hemodynamics in hypertensive patients were similar to previous reports (13), i.e., $C_{\text {In }}$ was in the normal range, being $117 \pm 18 \mathrm{ml} / \mathrm{min}$ per $1.73 \mathrm{~m}^{2}$ (mean $\pm 2 \mathrm{SEM}$ ) in the four patients on a high sodium intake. The PAH clearance was $518 \pm 100 \mathrm{ml} / \mathrm{min}$ per $1.73 \mathrm{~m}^{2}$ and the filtration fraction was $23.3 \pm 4.0 \%$.

During the hypertonic saline infusion in the hypertensive subjects on high sodium intake, $C_{\text {In }}$ tended to remain constant, while effective renal plasma flow $\left(\mathrm{C}_{\mathrm{PAB}}\right)$ rose, resulting in a progressive fall in filtration fraction to normal levels. These changes are demonstrated in the data from patient I. W. in Table I. In Table II is a comparison of renal hemodynamics between the normals and hypertensive groups at each of three levels of osmolar clearance shown previously. In the hypertensive subjects, the mean $C_{\text {In }}$ was $121 \mathrm{ml} /$ min per $1.73 \mathrm{~m}^{2}$ at a Cosm of $8.2 \mathrm{ml} / \mathrm{min}$ per $1.73 \mathrm{~m}^{2}$ and did not change significantly as Cosm increased to 24.2. In contrast, in the normal group there was a progressive rise in $C_{\text {In }}$ from $118 \pm 24$ at a $C_{\text {osm }}$ of $8.2 \mathrm{ml} / \mathrm{min}$ per $1.73 \mathrm{~m}^{2}$ to a value of $162 \pm 9 \mathrm{ml} / \mathrm{min}$ per $1.73 \mathrm{~m}^{2}$ at a $\mathrm{C}_{\text {som }}$ of 23.8. The difference in mean $\mathrm{C}_{\mathrm{In}}$ between the two groups was significant at the highest $C_{0 s m}(P<$ 0.01 ). There was a rise in $C_{P A B}$ in both the normal and hypertensive groups during the saline infusion. No significant difference between the two groups could be demonstrated.

The effect of hyperaldosteronism and potassium depletion. Two of our hypertensive patients subjected to hypertonic saline infusions during hydropenia had hyperaldosteronism and were potassium depleted at the time of study. To evaluate the effect of hyperaldosteronism and potassium depletion on the results, one of the patients (P. L.) was restudied $1 \mathrm{yr}$ after bilateral total adrenalectomy, at which time he continued to be hypertensive, but no longer had hyperaldosteronism or potassium depletion. Fig. 4 shows the $\mathrm{T}^{\circ} \mathrm{H}_{20}$ curve in this patient before and after surgery. It can be seen that

TABLE II

Effects of Saline Loading at Three Levels of Osmolar Clearance during Hydropenia

\begin{tabular}{|c|c|c|c|c|c|}
\hline & Com* & $\mathrm{T}^{\circ} \mathrm{H}_{80 *}$ & $\mathrm{C}_{\mathrm{In}^{*}}$ & $\mathrm{C}_{\mathrm{PAB}} \mathbf{B}^{*}$ & $\mathrm{C}_{\mathrm{Na}} / \mathrm{C}_{\mathrm{In}} \times 100$ \\
\hline & $m l / m i n$ & $m l / m i n$ & $m l / m i n$ & $m l / m i n$ & \\
\hline $\begin{array}{l}\text { Normal (5) } \\
\text { Hypertensive (4) }\end{array}$ & $\begin{array}{l}8.2 \pm 0.4 \\
8.2 \pm 0.6\end{array}$ & $\begin{array}{l}4.7 \pm 0.4 \\
3.5 \pm 0.8 \ddagger\end{array}$ & $\begin{array}{l}118 \pm 24 \\
121 \pm 24\end{array}$ & $\begin{array}{l}589 \pm 128 \\
628 \pm 120\end{array}$ & $\begin{array}{l}5.3 \pm 0.5 \\
5.5 \pm 0.8\end{array}$ \\
\hline $\begin{array}{l}\text { Normal (5) } \\
\text { Hypertensive (4) }\end{array}$ & $\begin{array}{l}17.0 \pm 0.8 \\
17.4 \pm 0.9\end{array}$ & $\begin{array}{l}7.1 \pm 0.8 \\
4.8 \pm 1.2 \ddagger\end{array}$ & $\begin{array}{l}128 \pm 10 \\
112 \pm 18\end{array}$ & $\begin{array}{l}736 \pm 134 \\
622 \pm 108\end{array}$ & $\begin{array}{l}11.8 \pm 1.6 \\
14.5 \pm 1.68\end{array}$ \\
\hline $\begin{array}{l}\text { Normal (5) } \\
\text { Hypertensive (3) }\end{array}$ & $\begin{array}{l}23.8 \pm 2.0 \\
24.2 \pm 2.3\end{array}$ & $\begin{array}{l}8.2 \pm 1.2 \\
5.2 \pm 1.28\end{array}$ & $\begin{array}{l}162 \pm 9 \\
121 \pm 15 \ddagger\end{array}$ & $\begin{array}{l}724 \pm 103 \\
682 \pm 126\end{array}$ & $\begin{array}{l}13.4 \pm 1.7 \\
18.5 \pm 0.8 \ddagger\end{array}$ \\
\hline
\end{tabular}

Data are means \pm 2 sEM. Abbreviations as in Table I.

* Values corrected to $1.73 \mathrm{~m}^{2}$ body surface area.

¥ Values different from normal subjects at the 0.01 level or better.

$\$$ Values different from normal subjects at the $0.01-0.05$ level. 


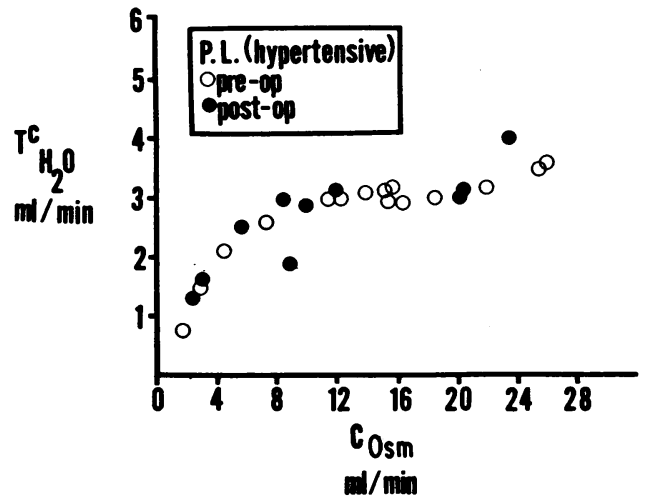

FIGURE 4 Hypertonic saline loading during hydropenia. Comparison of curves of free water reabsorption $\left(\mathrm{T}^{\mathrm{c}}{ }_{\mathrm{H}_{2} \mathrm{O}}\right)$ vs. osmolar clearance $\left(\mathrm{C}_{\mathrm{osm}}\right)$ in patient $\mathrm{P}$. L. who had hyperaldosteronism due to bilateral adrenal hyperplasia preoperatively (closed circles) and 1 year after total bilateral adrenalectomy (open circles).

they are virtually identical, suggesting that the defect was due to hypertension rather than to potassium depletion or hyperaldosteronism.

Studies during water diuresis

Hypotonic saline diuresis. Six normal, maximally hydrated subjects and four hypertensive patients (M. G.,
P. L., I. W., and R. O.) received infusions of hypotonic "saline," and a summary of the data obtained from the studies at comparable levels of diuresis is given in Table III. In the normal group, only four of the six subjects exhibited a measurable increment in $\mathrm{C}_{\mathrm{Na}} / \mathrm{C}_{\mathrm{In}}$ and in the fraction of filtered water excreted $\left(\mathrm{V} / \mathrm{C}_{\text {In }}\right)$. A similar difficulty in producing a diuresis in some normal human subjects has been observed previously by others (14). For purposes of comparing the data of the hypertensive patients with those of normal subjects, comparisons are made in Table III at an arbitrary increment in $\mathrm{V} / \mathrm{C}_{\mathrm{In}}$ of approximately $3.5-4.0 \mathrm{ml} / \mathrm{min}$ per $100 \mathrm{ml}$ of GFR, a value achieved by all hypertensive patients and all four of the normal individuals who manifested some degree of diuresis. It is clear from the table that even at a relatively small $\Delta\left(\mathrm{V} / \mathrm{C}_{\mathrm{In}}\right)$, the hypertensives responded in an exaggerated fashion with regards to $\mathrm{C}_{\mathrm{Na}} / \mathrm{C}_{\mathrm{In}}$, which rose $2-3 \mathrm{ml} / \mathrm{min}$ per $100 \mathrm{ml}$ of GFR in the hypertensives compared to a rise of 0.51.5 in normals. Filtration fraction was higher in the hypertensives during the control steady-state water diuresis, reflecting mainly a relatively greater reduction from normal in $\mathrm{C}_{\mathbf{P A B}}$ than in $\mathrm{C}_{\mathrm{In}}$, but no consistent changes in renal hemodynamics accompanied the increment in natriuresis in these studies after saline loading.

TABLE III

Hypotonic Saline Loading in Hydrated Normal and Hypertensive Subjects

\begin{tabular}{|c|c|c|c|c|c|c|c|c|c|}
\hline & \multicolumn{4}{|c|}{ Control* } & \multicolumn{5}{|c|}{ Hypotonic saline loading* } \\
\hline & $\mathrm{C}_{\mathrm{In}}$ & $\mathrm{C}_{\mathrm{PAH}}$ & $\mathrm{C}_{\mathrm{Na}} / \mathrm{C}_{\text {In }}$ & FF & $\Delta\left(\frac{V}{C_{I n}}\right) \times 100$ & $\mathrm{C}_{\text {In }}$ & CPAH & $\mathrm{C}_{\mathrm{Na}} / \mathrm{C}_{\mathrm{In}}$ & FF \\
\hline & $m l / \min$ & $m l / \min$ & & & & $\mathrm{ml} / \mathrm{min}$ & $m l / m i n$ & & \\
\hline \multicolumn{10}{|c|}{ Normal subjects } \\
\hline S S. & 114 & 723 & 0.41 & 0.16 & 3.7 & 134 & 920 & 1.04 & 0.15 \\
\hline M. D. & 112 & 658 & 1.42 & 0.17 & 3.6 & 142 & 880 & 2.80 & 0.16 \\
\hline D. B. & 78 & 522 & 0.81 & 0.15 & 3.4 & 85 & 575 & 1.41 & 0.15 \\
\hline J. McC. & 91 & 581 & 1.50 & 0.16 & 3.3 & 89 & 533 & 1.80 & 0.17 \\
\hline R. P.‡ & 112 & 490 & 1.01 & 0.23 & 0 & & & & \\
\hline R. M. $\ddagger$ & 110 & 654 & 1.11 & 0.17 & 0 & & & & \\
\hline Average & 103 & 605 & 1.04 & 0.17 & 3.5 & 113 & 727 & 1.76 & 0.16 \\
\hline \multicolumn{10}{|c|}{ Hypertensives } \\
\hline M. G. & 72 & 358 & 3.20 & 0.20 & 3.8 & 78 & 361 & 6.28 & 0.22 \\
\hline I. W. & 71 & - & 4.05 & - & 4.1 & 81 & 293 & 6.07 & 0.28 \\
\hline P. L. & 55 & 242 & 5.40 & 0.23 & 3.6 & 54 & 236 & 7.64 & 0.23 \\
\hline R. O. & 108 & 459 & 3.28 & 0.23 & 3.7 & 109 & 489 & 5.18 & 0.22 \\
\hline Average & 77 & 353 & 3.98 & 0.22 & 3.8 & 81 & 345 & 6.29 & 0.24 \\
\hline
\end{tabular}

Abbreviations as in Table $\mathrm{I} . \mathrm{V}=$ urine flow; FF = filtration fraction.

* Control data are means of two to three periods before saline loading. Data during saline loading are selected at an arbitrary increment of $\mathrm{V} / \mathrm{C}_{\mathrm{In}}$ of approximately $3.5-4.0 \mathrm{ml} / \mathrm{min}$ per $100 \mathrm{ml}$ of $\mathrm{GFR}$, common to both normal and hypertensive groups. $\ddagger$ In these subjects no natriuresis or diuresis was observed after the infusion of more than $2000 \mathrm{ml}$ of hypotonic saline. 


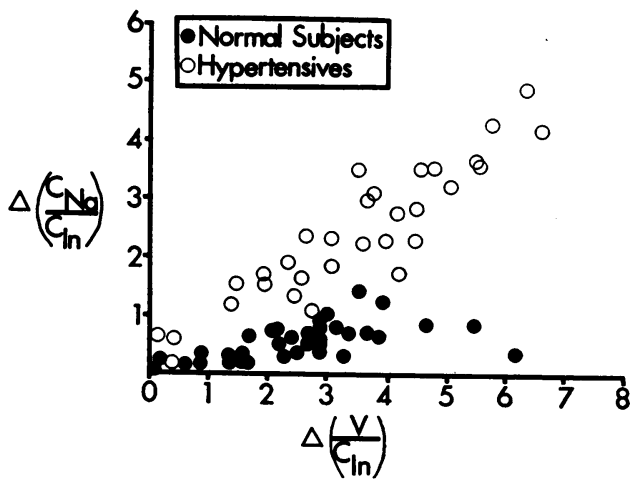

FIgure 5 Hypotonic saline loading during water diuresis. Relationship between changes in percentage of filtered sodium excreted $\left[\Delta\left(\mathrm{C}_{\mathrm{Na}} / \mathrm{C}_{\mathrm{In}}\right)\right]$ and changes in urine flow per $100 \mathrm{ml}$ of glomerular filtrate $\left[\Delta\left(\mathrm{V} / \mathrm{C}_{\mathrm{In}}\right)\right]$ in normal subjects (closed circles) and hypertensives (open circles).

The details of the differences between the normal and hypertensive group regarding $\mathrm{C}_{\mathrm{Na}_{\mathrm{a}}} / \mathrm{C}_{\mathrm{In}}$ are illustrated in Fig. 5 in which increments of $\mathrm{C}_{\mathrm{Na}} / \mathrm{C}_{\mathrm{In}}$ in response to saline loading are plotted against corresponding increments in $\mathrm{V} / \mathrm{C}_{\text {In }}$ for both groups. Analysis of covariance showed that at any level of $\Delta\left(\mathrm{V} / \mathrm{C}_{\mathrm{In}}\right)$, the $\Delta\left(\mathrm{C}_{\mathrm{Na}_{\mathrm{a}}} / \mathrm{C}_{\mathrm{In}}\right)$ was greater in the hypertensive group $(P<0.001)$. Since the slopes of the regression lines of the two populations are significantly different, the difference in $\mathrm{C}_{\mathrm{Na}} /$ $\mathrm{C}_{\text {In }}$ between the two groups is magnified at greater degrees of diuresis. It is also clear that in hydrated normal subjects, in contrast to hypertensives, it is extremely difficult to achieve a natriuresis greater than $1 \%$ of filtered load of sodium.

Fig. 6 summarizes the results comparing changes in $\mathrm{C}_{\mathrm{H}_{2} \mathrm{O}} / \mathrm{C}_{\text {In }}$ resulting from hypotonic saline loading to corresponding changes in $\mathrm{V} / \mathrm{C}_{\mathrm{In}}$ in both normal and hypertensive subjects. In the maximally hydrated sub-

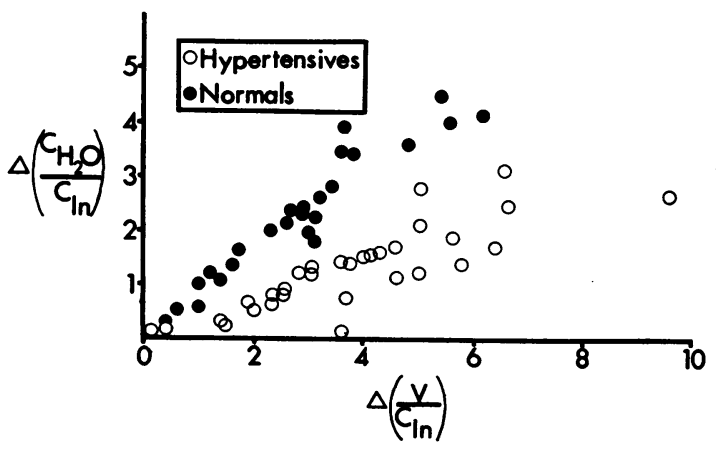

Figure 6 Hypotonic saline loading during water diuresis. Relationship between changes in free water clearance per 100 $\mathrm{ml}$ of glomerular filtrate $\left[\Delta\left(\mathrm{C}_{\mathrm{H}_{2} \mathrm{O}} / \mathrm{C}_{\mathrm{In}}\right)\right]$ and changes in urine flow per $100 \mathrm{ml}$ of glomerular filtrate $\left[\Delta\left(\mathrm{V} / \mathrm{C}_{\mathrm{In}_{\mathrm{n}}}\right)\right]$ in normal subjects (closed circles) and hypertensives (open circles).

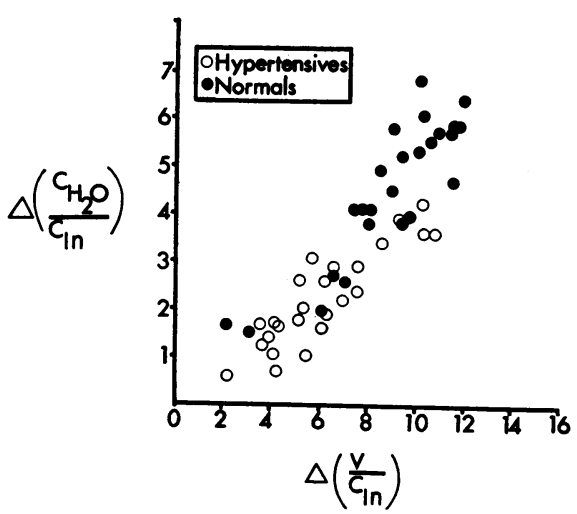

FIGURE 7 Acetazolamide administration during water diuresis. Relationship between changes in free water clearance per $100 \mathrm{ml}$ of glomerular filtrate $\left[\Delta\left(\mathrm{C}_{\mathrm{H}_{2} \mathrm{O}} / \mathrm{C}_{\mathrm{In}_{\mathrm{n}}}\right)\right]$ and changes in urine flow per $100 \mathrm{ml}$ of glomerular filtrate $\left[\Delta\left(\mathrm{V} / \mathrm{C}_{\mathrm{In}}\right)\right]$ in normal subjects (closed circles) and hypertensives (open circles).

ject, $\mathrm{V} / \mathrm{C}_{\mathrm{In}}$ is an approximation of the fraction of filtered sodium delivered out of the proximal tubule to the diluting segments (15). Therefore, $\Delta\left(\mathrm{V} / \mathrm{C}_{\text {In }}\right)$ in response to saline loading represents increments in delivery of sodium to the loop of Henle. Similarly $\Delta\left(\mathrm{C}_{\mathrm{H}_{2} \mathrm{O}} / \mathrm{C}_{\mathrm{In}}\right)$ represents primarily increments in fraction of filtered sodium reabsorbed at the distal diluting sites. Fig. 6 shows that at any $\Delta\left(\mathrm{V} / \mathrm{C}_{\mathrm{In}}\right)$, increments in $\mathrm{CH}_{\mathrm{H}_{2}} / \mathrm{C}_{\mathrm{In}}$ are significantly less in the hypertensive patients compared to controls $(P<0.001)$. Therefore, the "exaggerated natriuresis" of hypertensive hydrated patients occurs pari passu with a defect in $\mathrm{C}_{\mathrm{H}_{2} \mathrm{O}}$.

Acetazolamide diuresis. Since the infusion of hypotonic saline by necessity causes extracellular fluid volume expansion which may have effects on sodium reabsorption in the loop of Henle $(15,16)$, the acetazolamide studies were performed to evaluate the response of increased delivery of sodium per se to the loop in the absence of volume expansion. This agent increases distal sodium delivery by blocking sodium and bicarbonate reabsorption in the proximal tubule (17-19).

Fig. 7 illustrates a composite plot of $\Delta\left(\mathrm{V} / \mathrm{C}_{\mathrm{In}}\right)$ vs. $\Delta\left(\mathrm{C}_{\mathrm{H}_{2} \mathrm{O}} / \mathrm{C}_{\mathrm{In}}\right)$ in five normal subjects and in four hypertensive patients given acetazolamide during a maximal sustained water diuresis. It can be seen that larger increments in delivery to the loop are obtained by acetazolamide in normal subjects than by hypotonic saline infusions (Fig. 6), and that there is a linear increase in $\Delta\left(\mathrm{C}_{\mathrm{H}_{2} \mathrm{O}} / \mathrm{C}_{\mathrm{In}}\right)$ as $\Delta\left(\mathrm{V} / \mathrm{C}_{\mathrm{In}}\right)$ increases in both the normal and hypertensive subjects,. In these studies, in contrast to the saline loading experiments, the difference between the normal and hypertensive group was barely significant at the 0.05 level utilizing analysis of covariance. 


\section{DISCUSSION}

The results show that during saline loading in the presence of an exaggerated natriuresis, $\mathrm{T}^{\mathrm{c}}{ }_{\mathrm{H}_{2} \mathrm{O}}$ and $\mathrm{C}_{\mathrm{H}_{2} \mathrm{O}}$ are abnormally low in hypertensive patients. These studies were designed to evaluate both of these variables under conditions of increased delivery of sodium to the loop of Henle with and without volume expansion. Since $T_{\mathrm{H}_{2} \mathrm{O}}^{\mathbf{c}}$ is a function of the rate of medullary sodium accumulation during hydropenia, and $\mathrm{C}_{\mathrm{H}_{2} \mathrm{O}}$ is an index of the rate of sodium removal from tubular fluid at water-impermeable sites, then changes in both of these variables reflect changes in sodium transport in the loop of Henle (20).

In the hydropenic studies it was assumed that the infusion of hypertonic saline resulted in increased delivery of sodium to the loop by: (a) decreasing proximal tubular sodium reabsorption (4-6); and $(b)$ by increasing the filtered load of sodium due to an increasing plasma sodium concentration and a rise in GFR. Under these conditions, both a quantitative and qualitative difference in $\mathrm{T}^{\mathrm{c}}{ }_{\mathrm{H}_{2} \mathrm{O}}$ as a function of $\mathrm{Cosm}_{\mathrm{sm}}$ were shown between the hypertensive and the normal groups. In the hypertensive patients, $T^{\mathbf{c}}{ }_{\mathrm{H}_{2} \mathrm{O}}$ rose initially, then reached a plateau, or an apparent limit, and did not rise further as Cosm continued to rise. By contrast, in the normal subject $\mathrm{T}^{\mathrm{c}} \mathrm{H}_{2} \mathrm{O}$ rose curvilinearly without evidence of a limit (9). Furthermore, the average $\mathrm{T}^{\mathbf{c}} \mathrm{H}_{2} \mathrm{O}$ in the hypertensive group was significantly lower at any given Cosm than in the normal group. Also, in the hydropenic studies, the fraction of filtered sodium excreted was higher in the hypertensive subjects than in the normals, indicating an over-all decrease in tubular sodium reabsorption in the hypertensives. This observation, together with the defect in $\mathrm{T}^{\mathrm{c}} \mathrm{H}_{2} \mathrm{O}$, suggests that the site in the nephron of reduced tubular sodium reabsorption was, at least in part, the ascending loop of Henle.

However, the interpretation of these results is complicated by the fact that during hydropenia, calculated $\mathrm{T}^{\mathrm{c}} \mathrm{H}_{2 \mathrm{O}}$ is influenced by factors other than sodium reabsorption in the loop of Henle, such as the rate of medullary blood flow, the permeability of the collecting ducts to water, and the extent to which tubular fluid attains isotonicity at the end of the distal tubule (21).

Therefore, alternative interpretations of the results during hydropenia are possible. For example, the decreased tubular sodium reabsorption in hypertensives could occur primarily in the proximal tubule, with the apparent defect in $\mathrm{T}^{\mathrm{c}} \mathrm{H}_{2} \mathrm{O}$ being due to altered permeability of the epithelium of the distal tubule and collecting duct to water.

The results obtained during the hydration studies provide additional information to help differentiate between the alternatives discussed above. In subjects undergoing a water diuresis, we assumed that the increase in $\mathrm{V} / \mathrm{C}_{\text {In }}$ brought about by hypotonic saline infusion was primarily due to a decrease in proximal tubular sodium reabsorption and/ or a rise in $\mathrm{C}_{\mathbf{I n}}$. If this assumption is valid, then increments in $\mathrm{V} / \mathrm{C}_{\text {In }}$ are an approximation of increments in delivery of sodium to the loop, and increments in $\mathrm{C}_{\mathrm{H}_{2} \mathrm{O}} / \mathrm{C}_{\mathrm{In}}$ are an approximation of increments of the fraction of filtered sodium reabsorbed in the loop and other diluting segments. Interpreted in this way, the results during hypotonic saline infusion indicate that for any given increment of sodium delivered, less sodium is reabsorbed distally by the hypertensive subject. These observations on $\mathrm{C}_{\mathrm{H}_{2} \mathrm{O}}$ during hydration indicate, therefore, that the defect in $\mathrm{T}^{\mathrm{c}} \mathrm{H}_{2} \mathrm{O}$ observed during saline loading in hydropenic hypertensive patients is also mainly due to a decrease in the rate of sodium reabsorption in the loop of Henle at any level of delivery.

The changes in $\mathrm{T}^{\mathbf{c}}{ }_{\mathrm{H}_{2} \mathrm{O}}$ in the sodium-depleted hypertensive patients are also interpretable in terms of an impairment in sodium reabsorption in the loop of Henle. The marked abnormality in $\mathrm{T}^{\mathbf{c}}{ }_{\mathrm{H}_{2} \mathrm{O}}$ formation (including the excretion of $\mathrm{C}_{\mathrm{H}_{2} \mathrm{O}}$ ) during hydropenia could have been due to a limitation to the rate of medullary sodium accumulation as a consequence of two factors: $(a)$ a reduced load of sodium to the loop of Henle, and $(b)$ the inability of the sodium pump in the loop to respond normally to even small increments of sodium from the proximal tubule. If complete isosmotic equilibration does not occur in the late distal tubule in man, as is the case in the dog (22), then the reduced rate of osmotic water reabsorption from the collecting duct would account for the observations in sodium-depleted hypertensive man.

This defect in loop sodium reabsorption in hypertension is characterized further by the acetazolamide studies. The administration of this drug caused increased delivery of sodium to the loop without volume expansion. In contrast to saline loading, the increment in $\mathrm{C}_{\mathrm{H}_{2} \mathrm{O}} / \mathrm{C}_{\mathrm{In}}$ (and presumably in the fraction of filtered sodium reabsorbed at the diluting segments) with increasing rates of sodium delivery either was no different in the hypertensives compared to the normal group, or if present, the difference between the two groups was of borderline quantitative significance. This indicates that some effect of acute extracellular volume expansion per se is largely responsible for the abnormality in sodium transport in the loop. In the absence of expansion little or no intrinsic defect in distal sodium reabsorption appears to be present.

Baldwin, Gombos, and Chassis (23) found a defect in $\mathrm{T}^{\mathbf{c}}{ }_{\mathrm{H}_{2} \mathrm{O}}$ in hypertensive patients undergoing mannitol diuresis which was corrected at high rates of $\mathrm{Cosm}_{\mathrm{m}}$, suggesting to these authors that proximal tubular sodium reabsorption was excessive in essential hypertension.

Exaggerated Natriuresis in Hypertension

1013 
Similarly, Steinmetz et al. could find no abnormality in $\mathrm{C}_{\mathrm{H}_{2} \mathrm{O}}$ during mannitol diuresis in hydrated hypertensives (24). While the explanation for the discrepancy between these studies and ours is not clear, it is interesting to note that Mertz (25) found a defect in the concentrating capacity of the kidney in hypertensives only during hypertonic saline diuresis and not with mannitol loading. He found that the variability of the mannitol data was such that he was unable to detect any difference in $\mathrm{T}_{\mathrm{H}_{2} \mathrm{O}}^{\mathrm{O}}$ between normals and hypertensives. Furthermore, Cannon (26) found that $\mathrm{C}_{\mathrm{H}_{2} \mathrm{O}}$ was decreased at any $\mathrm{V}$ in hypertensive subjects given infusions of dextrose in water. He reached a conclusion similar to ours, although the response of the distal nephron to increased loads of sodium was not evaluated in these studies.

The precise mechanism of the defective sodium reabsorption in the loop of Henle in hypertension is not clear from these studies. Although much work has been done on a variety of factors affecting sodium reabsorption in the proximal tubule, very little is known about the effect of these or other factors on sodium reabsorption in the loop of Henle. It is reasonable to propose that the abnormal elevation of arterial blood pressure of the hypertensive patient in some way is responsible for the defect in loop sodium transport and the exaggerated natriuresis. It has been shown by a number of investigators that over-all tubular sodium reabsorption can be decreased by increasing renal perfusion pressure (2729 ), and this effect seems to occur at least partially in the proximal tubule $(30,31)$. Earley and Friedler, however, demonstrated that elevation of systemic blood pressure caused a natriuresis only in the presence of renal artery vasodilatation (27). It is well established that patients with hypertension have generalized renal vasoconstriction, manifested by a decrease in renal blood flow and an increased filtration fraction (13). Therefore, according to the proposal of Earley and Friedler (27), hypertensive subjects would not be expected to have decreased tubular sodium reabsorption on the basis of elevated blood pressure unless renal vasodilatation occurred. In our hydropenic, hypertensive subjects during hypertonic saline diuresis, $C_{P A B}$ increased and the filtration fraction fell to the normal range (Tables I and II) as Cosm increased, indicating that volume expansion did cause some degree of vasodilatation. Under these conditions, if medullary vasodilatation also occurred in parallel with rises in $C_{P A B}$, the increased perfusion pressure of the hypertensive patient might be transmitted to the renal vascular bed, causing an increased intracapillary pressure in the vasa recta and a resultant impairment in sodium transport in the loop of Henle. However, in the hypotonic saline studies in the hydrated patients a definite defect was present in loop sodium reabsorption without a consistent rise in $\mathrm{C}_{\mathbf{P A B}}$. It has been

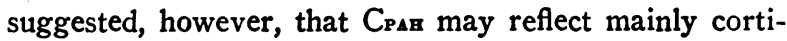
cal plasma flow and not medullary flow (32). Therefore, it is still possible that an abnormal increase in hydrostatic pressure could have occurred in the vasa recta of hypertensive patients, if for some reason saline loading selectively produced a medullary vasodilatation as compared to normal subjects. One preliminary report has provided data suggesting that a rise in renal interstitial pressure presumably associated with a vasodilatation occurred in response to saline loading (33).

The possibility that a humoral factor other than adrenal mineralocorticoids may be important in the control of tubular sodium reabsorption has been raised by a number of investigators (34-37). Cort and Lichardus claimed to have demonstrated the presence of such a factor in hypertensive patients after the infusion of dextran (35). According to their hypothesis, volume expansion in hypertensives causes an increase in the "central blood volume" where stretch receptors are located which signal the release of a natriuretic hormone. Our data do not permit any speculation as to the importance of a natriuretic hormone in influencing sodium reabsorption in the loop of Henle in hypertensive subjects.

Potassium depletion by itself may cause a defect in sodium reabsorption in the loop of Henle (38). Two of our patients were potassium depleted at the time of study due to hyperaldosteronism. However, one of these patients was studied postoperatively, after correction of the potassium depletion, but when he was still hypertensive. The defect in $\mathrm{T}^{\mathbf{c}}{ }_{\mathbf{H}_{2} \mathrm{O}}$ did not improve after surgery indicating that potassium depletion had played no major role in the results obtained before surgery. Furthermore, no evidence existed to suggest that our patients with essential hypertension were potassium depleted before the study.

Although the mechanism of the alteration in loop of Henle sodium transport is not clear, it appears that the hypertensive subject provides another example of the importance of the relationship between the proximal tubule and the loop of Henle in controlling sodium excretion. As already discussed, a variety of factors may decrease the fraction of the filtered sodium reabsorbed in the proximal tubule. A defect in loop of Henle sodium reabsorption under conditions of increased delivery of sodium to the loop during acute volume expansion appears to be characteristic of hypertensive patients. This mechanism is a major factor in the alteration in sodium excretion in hypertensive patients referred to as "exaggerated natriuresis."

Finally, we should point out that our studies do not exclude an impairment also in proximal tubular sodium reabsorption which contributes to the natriuresis of hypertensives. Our experiments were not designed specifi- 
cally to evaluate this possibility. However, the fact that saline loading can produce consistently greater absolute increases in $\mathrm{V}$ and $\mathrm{V} / \mathrm{C}_{\mathrm{In}}$ in hydrated hypertensives compared to normal subjects argues strongly in favor of a decreased capacity of the proximal tubule to reabsorb sodium in the hypertensive patients under these experimental conditions. Despite this possibility, however, it is clear from an inspection of Figs. 5 and 6, that the defect in $\mathrm{C}_{\mathrm{H}_{2} \mathrm{O}}$ and hence in distal sodium transport in the hypertensives can account for most of the extra sodium excreted during the exaggerated natriuresis after saline infusions.

\section{ACKNOWLEDGMENTS}

We thank Miss Dolores Metz, Mrs. Jean Tschorn, Miss Marta Pavlinsky, Miss Elizabeth Cameron, and Miss Cordelia Shute and her nursing staff for technical and nursing assistance. We are grateful to Lidia Kosolopovs, Leonid Kosolopovs, Catherine Wisnewski, and Carmen DiAngelo for the laboratory analyses and Miss Vivian Wang for preparing the special diets.

This investigation was supported by Grants HE 00340, HE 07284, 2 MO1 FR 40, and FR 15 from the National Institutes of Health. Dr. Buckalew's work was performed during tenure of a U. S. Public Health Service Special Fellowship 1 F3 AM 22,818-01. This work was performed during tenure of U. S. Public Health Service Postdoctoral Fellowships 1F2 AM 35,910 (Dr. Kintzel) and 1F2 AM 32,342-01 (Dr. Puschett). Dr. Goldberg was supported by Research Career Development Award 2 K3 AM 18,582 from the National Institute of Arthritis and Metabolic Disease, National Institutes of Health.

\section{REFERENCES}

1. Farnsworth, E. B., and M. H. Barker. 1943. Tubular resorption of chloride in hypertensive and in normal individuals. Proc. Soc. Exp. Biol. Med. 52: 74.

2. Baldwin, D. S., A. W. Biggs, W. Goldring, W. H. Hulet, and H. Chasis. 1958. Exaggerated natriuresis in essential hypertension. Amer. J. Med. 24: 893.

3. Cottier, P. T., J. M. Weller, and S. W. Hoobler. 1958. Effect of an intravenous sodium chloride load on renal hemodynamics and electrolyte excretion in essential hypertension. Circulation. 17: 750.

4. Dirks, J. H., W. J. Cirksena, and R. W. Berliner. 1965. The effect of saline infusion on sodium reabsorption by the proximal tubule of the dog. J. Clin. Invest. 44: 1160.

5. Rector, F. C., Jr., J. C. Sellman, M. Martinez-Maldonado, and D. W. Seldin. 1967. The mechanism of suppression of proximal tubular reabsorption by saline infusions. J. Clin. Invest. 46: 47.

6. Cortney, M. A., M. Mylle, W. E. Lassiter, and C. W. Gottschalk. 1965. Renal tubular transport of water, solute and $\mathrm{PAH}$ in rats loaded with isotonic saline. Amer. J. Physiol. 209: 1199.

7. Landwehr, D. M., R. M. Klose, and G. Giebisch. 1967. Renal tubular sodium and water reabsorption in the isotonic sodium chloride-loaded rat. Amer. J. Physiol. 212: 1327.

8. Lindheimer, M. D., R. C. Lalone, and N. G. Levinsky. 1967. Evidence that an acute increase in glomerular filtration has little effect on sodium excretion in the dog unless extracellular volume is expanded. J. Clin. Invest. 46: 256.

9. Goldberg, M., D. K. McCurdy, and M. A. Ramirez. 1965. Differences between saline and mannitol diuresis in hydropenic man. J. Clin. Invest. 44: 182.

10. Howards, S. S., B. B. Davis, F. G. Knox, F. S. Wright, and R. W. Berliner. 1968. Depression of fractional sodium reabsorption by the proximal tubule of the dog without sodium diuresis. J. Clin. Invest. 47: 1561.

11. Goldberg, M. 1963. Abnormalities in the renal excretion of water. Pathophysiology and differential diagnosis. Med. Clin. N. Amer. 47: 915.

12. Snedecor, G. W. Statistical Methods. The Iowa State University Press, Ames. 1956.

13. Goldring, W., H. Chasis, H. A. Ranges, and H. W. Smith. 1941. Effective renal blood flow in subjects with essential hypertension. J. Clin. Invest. 20: 637.

14. Lenz, P. R., M. H. Goldstein, and M. F. Levitt. 1967. Effect of an acute salt surfeit on proximal tubular (PT) reabsorption in normal man. J. Clin. Invest. 46: 1084. (Abstr.)

15. Eknoyan, G., W. N. Suki, F. C. Rector, Jr., and D. W. Seldin. 1967. Functional characteristics of the diluting segment of the dog nephron and the effect of extracellular volume expansion on its reabsorptive capacity. J. Clin. Invest. 46: 1178.

16. Stein, R. M., R. G. Abramson, T. Kahn, and M. F. Levitt. 1967. Effects of hypotonic saline loading in hydrated dog: evidence for a saline-induced limit on distal tubular sodium transport. J. Clin. Invest. 46: 1205.

17. Dirks, J. H., W. J. Cirksena, and R. W. Berliner. 1966. Micropuncture study of the effect of various diuretics on sodium reabsorption by the proximal tubules of the dog. J. Clin. Invest. 45: 1875.

18. Counihan, T. B., B. M. Evans, and M. D. Milne. 1954. Observations on the pharmacology of the carbonic anhydrase inhibitor "Diamox." Clin. Sci. 13: 583.

19. Puschett, J. B., and M. Goldberg. 1968. The acute effects of furosemide on acid and electrolyte excretion in man. J. Lab. Clin. Med. 71: 666.

20. Goldberg, M., D. K. McCurdy, E. L. Foltz, and L. W. Bluemle, Jr. 1964. Effects of ethacrynic acid (a new saliuretic agent) on renal diluting and concentrating mechanisms: evidence for side of action in the loop of Henle. J. Clin. Invest. 43: 201.

21. Berliner, R. W., and C. M. Bennett. 1967. Concentration of urine in the mammalian kidney. Amer. J. Med. 42: 777.

22. Clapp, J. R., and R. R. Robinson. 1966. Osmolality of distal tubular fluid in the dog. J. Clin. Invest. 45: 1847.

23. Baldwin, D. S., E. A. Gombos, and H. Chasis. 1965. Urinary concentrating mechanism in essential hypertension. Amer. J. Med. 38: 864.

24. Steinmetz, P. R., R. P. Eisinger, E. A. Gombos, H. Chasis, and D. S. Baldwin. 1964. Excretion of free water and solute during maximal water diuresis and normal and hypertensive subjects. J. Lab. Clin. Med. 64: 238.

25. Mertz, D. P. 1966. The concentrating power of the kidneys in essential hypertension. German Med. Mon. 11: 125.

26. Cannon, P. J. 1968. Effects of five per cent dextrosewater infusions in normal and hypertensive man: evidence for increased proximal and distal tubular sodium rejection by hypertensive patients and its relation to renal hemodynamics. Circulation. 37: 832.

Exaggerated Natriuresis in Hypertension

1015 
27. Earley, L. E., and R. M. Friedler. 1966. The effect of combined renal vasodilatation and pressor agents on renal hemodynamics and tubular reabsorption of sodium. J. Clin. Invest. 45 : 542.

28. McDonald, S. J., and H. E. de Wardener. 1965. The relationship between the renal arterial perfusion pressure and the increase in sodium excretion which occurs during an infusion of saline. Nephron. 2: 1 .

29. Selkurt, E. E., I. Womack, and W. N. Dailey. 1965. Mechanism of natriuresis and diuresis during elevated renal arterial pressure. Amer. J. Physiol. 209: 95.

30. Earley, L. E., J. A. Martino, and R. M. Friedler. 1966. Factors affecting sodium reabsorption by the proximal tubule as determined during blockade of distal sodium reabsorption. J. Clin. Invest. 45: 1668.

31. Koch, K. M., H. S. Aynedjian, and N. Bank. 1968. Effect of acute hypertension on sodium reabsorption by the proximal tubule. J. Clin. Invest. 47: 1969.

32. Reubi, F. 1958. Objections a la theorie de la séparation intrarénal des hématies et du plasma. Helv. Med. Acta. 25: 516.

33. Lowenstein, J., E. Beranbaum, R. H. McShane, H. Chasis, and D. S. Baldwin. 1968. Renal interstitial pres- sure during exaggerated natriuresis in essential hypertension. J. Clin. Invest. 47: 63a. (Abstr.)

34. Davis, J. O., C. I. Johnston, S. S. Howards, and F. S. Wright. 1967. Humoral factors in the regulation of renal sodium excretion. Fed. Proc. 26: 60.

35. Cort, J. H., and B. Lichardus. 1963. The nature of the renal response to carotid-sinus pressor reflex. In Hormones and the Kidney. Peter C. Williams, editor. Academic Press Inc., London. 25.

36. Mills, I. H., H. E. de Wardener, C. J. Hayter, and W. F. Clapham. 1961. Studies on the afferent mechanism of the sodium chloride diuresis which follows intravenous saline in the dog. Clin. Sci. 21: 259.

37. Rector, F. C., Jr., M. Martinez-Maldonado, N. A. Kurtzman, J. C. Sellman, F. Oerther, and D. W. Seldin. 1968. Demonstration of hormonal inhibitor of proximal tubular reabsorption during expansion of extracellular volume with isotonic saline. J. Clin. Invest. 47: 761.

38. Buckalew, V. M., Jr., M. A. Ramirez, and M. Goldberg. 1967. Free water reabsorption during solute diuresis in normal and potassium depleted rats. Amer. J. Physiol. 212: 381 . 